\title{
Small intestinal permeability to mannitol and lactulose in the three ethnic groups resident in West Birmingham
}

\author{
T H Iqbal, K O Lewis, J C Gearty, B T Cooper
}

\begin{abstract}
Background/Aims-Asymptomatic residents of tropical countries have differences in small intestinal morphology and permeability compared with residents of temperate zones. The aim of this study was to investigate small intestinal permeability and morphology in three ethnic groups resident in Birmingham, UK. Methods-28 white patients, 101 Indian (Indian subcontinent), and 49 AfroCaribbean adult patients with dyspepsia had endoscopic distal duodenal biopsies and a hyperosmolar lactulose/mannitol permeability test. Twenty normal white subjects had the permeability test.

Results-Lactulose/mannitol excretion ratios (LMER) were: white subjects 0.022 (median), white patients 0.022 , Indians 0.031, Afro-Caribbeans 0.033. Differences between the immigrant groups and the two white groups were significant $(p<0.001)$; $33 \%$ of Indians and $45 \%$ of AfroCaribbeans had LMER outside the range of the white groups. Afro-Caribbeans born in the UK had significantly lower LMER than those born abroad $(p<0.05)$; a similar trend was seen in Indians. Villous height/mucosal thickness ratios, calculated from small intestinal biopsy specimens, were lower in the immigrant groups and correlated inversely with LMER $(r=0.28 ; p<0.05)$. Time resident in the tropics also correlated inversely with LMER.
\end{abstract}

Conclusions-There were significant differences in small intestinal permeability and morphology between immigrants resident in a Western country and the native white population. The data suggested that these differences were related to environmental factors.

(Gut 1996; 39: 199-203)

Keywords: small intestine, permeability, mannitol, lactulose, ethnic groups.

Gastroenterology Unit, City Hospital,

Birmingham

T H Iqbal

K O Lewis

J C Gearty

B T Cooper

Correspondence to: Dr B T Cooper,

Gastroenterology Unit,

Gastroenterology Unit, Birmingham B18 7QH.

Accepted for publication 27 February 1996 small intestinal structure compared with asymptomatic residents of temperate zones. ${ }^{12}$ These differences consist of minor degrees of villous broadening and shortening and infiltration of the epithelium and lamina propria by leucocytes. ${ }^{2}$ These differences have been

Since the widespread adoption of peroral small intestinal biopsy techniques it has become termed 'tropical enteropathy' and occur in otherwise healthy people in contrast with 'tropical sprue,' which causes symptomatic malabsorption. ${ }^{3}$ There is evidence that emigrants from non-tropical countries living in the tropics develop similar changes. American soldiers serving in Vietnam developed 'tropical jejunitis,' which improved within six months of their return to the United States. ${ }^{4}$ Asymptomatic American Peace Corps volunteers stationed in Pakistan had changes similar to tropical enteropathy, ${ }^{5}$ which developed within six months of arrival in the country. Those members of the Peace Corps not living in 'native' conditions but maintaining a 'protected' lifestyle at a nearby American base had less pronounced changes. ${ }^{5}$ The small intestinal morphology returned to normal 'non-tropical' appearances within 14 months of return to the USA. $^{6}$ In expatriate Pakistanis resident in New York City there was a trend for small intestinal morphology and xylose absorption to 'improve' with continued residence in temperate climes. ${ }^{7}$ Studies on asymptomatic expatriates from the West Indies showed that xylose malabsorption tended to be less in those who had lived for longer in the United States; however, jejunal biopsy was normal in nine of 11 subjects with xylose malabsorption who had a biopsy. ${ }^{8}$ Recent work from our unit has demonstrated small bowel morphological appearances consistent with a diagnosis of tropical enteropathy among immigrants from the tropics resident in Birmingham, UK. ${ }^{9}$

Xylose absorption has been widely used as a test of small intestinal function over the past 40 years. The absorption of this pentose was shown to be dramatically reduced in tropical sprue $^{10}$ and it was subsequently found that minor degrees of malabsorption of xylose were comparatively common in otherwise normal, asymptomatic residents of the tropics having morphological appearances of tropical enteropathy. ${ }^{1211}$ However, the use of this pentose alone as a marker of small intestinal function has several drawbacks. Xylose is absorbed both by passive and carrier mediated routes ${ }^{12}$ and it is metabolised to a certain extent in the body with only approximately $40 \%$ of an injected dose being recovered in the urine in humans. ${ }^{10}$ Urinary recovery of a single compound after oral ingestion is dependent on gastric emptying, renal function, and reliability of urine collection. For these reasons, xylose absorption tests have fallen out of favour and permeability tests using pairs of passively permeating molecules are increasingly being used to assess small intestinal integrity. Permeability is 
measured by studying the absorption of passively transported metabolically inert probe molecules. ${ }^{13}$ These molecules are often used in combination, which avoids the problems outlined above that can be associated with the use of a single marker. ${ }^{14}$ Studies using nonmetabolised sugar markers ${ }^{1516}$ have demonstrated changed small intestinal permeability in asymptomatic adult residents of the tropics compared with white residents of temperate zones. To date there have been no studies of small intestinal permeability in asymptomatic subjects of tropical origin resident in temperate climes.

Therefore the aims of this study were to investigate small intestinal permeability and morphology of two ethnic groups of immigrant origin resident in Birmingham, $\mathrm{UK}$ and to investigate any relations between small intestinal permeability, small bowel morphology, demographic factors, and diet.

\section{Methods}

SUBJECTS

Table I shows the age, sex, and race of the subjects studied. Twenty healthy white hospital employees served as normal controls for the intestinal permeability test. The patients were recruited at the time of upper gastrointestinal endoscopy for dyspepsia. Twenty eight white, 101 Indian (74 from Punjab; 27 from Bangladesh), and 49 Afro-Caribbean patients took part. No patient had symptoms or signs of intestinal disease (such as coeliac or Crohn's disease) or diabetes mellitus and none was taking non-steroidal anti-inflammatory drugs.

In addition to these groups, two male and three female white patients (mean age 50 ) with untreated coeliac disease served as 'disease controls' for the permeability studies.

\section{PERMEABILITY TEST}

Subjects were asked to fast from midnight and to avoid alcohol and milk and milk products (such as yoghurt and cheese) for 24 hours prior to the test. On the morning of the test the hyperosmolar test solution (1070 mosm) consisting of $10 \mathrm{~g}$ lactulose (a disaccharide $\mathrm{MW}$ 342) and $2.5 \mathrm{~g}$ mannitol (a sugar alcohol MW 181) dissolved in $50 \mathrm{ml}$ distilled water was ingested. Subjects were asked to refrain from eating and drinking for a further two hours and then allowed to eat and drink freely (avoiding milk/milk products and alcohol for the duration of test). A six hour urine collection was made and an aliquot stored at $-20^{\circ} \mathrm{C}$ until analysis for lactulose and mannitol using high performance liquid chromatography and

TABLE I Subjects

\begin{tabular}{lclll}
\hline & Number & UK born & Sex $(M / F)$ & Age mean (range) \\
\hline White controls & 20 & 20 & $11 / 9$ & $20(22-32)$ \\
White patients & 28 & 28 & $9 / 19$ & $42(17-77)$ \\
Indian patients & 101 & 18 & $50 / 61$ & $40(15-77)$ \\
Afro-Caribbean patients & 49 & 11 & $16 / 33$ & $47(19-77)$ \\
\hline
\end{tabular}

pulsed amperometric detection, using cellobiose and arabinose as internal standards. ${ }^{17}$ Results were expressed as six hour total lactulose to mannitol excretion ratios (LMER). Patients underwent a small intestinal lactulose/mannitol intestinal permeability test within two weeks of endoscopy.

\section{SMALL BOWEL MORPHOLOGY}

At upper gastrointestinal endoscopy, an approximately $10 \mathrm{mg}$ pinch biopsy specimen was taken from the junction of the second and third parts of the duodenum using Olympus $13 \mathrm{~K}$ biopsy forceps. This was oriented with the villous surface uppermost on nylon micro filament mesh (Schuco International, London), examined under the dissecting microscope, and fixed in formalin. The specimens were then embedded in paraffin wax; $3 \mu \mathrm{m}$ sections were cut and stained with haematoxylin and eosin. The stained sections were then examined by light microscopy. Only adequately oriented specimens (that is, those having five adjacent non-tangentially sectioned villi) were deemed suitable for computer aided image analysis.

Computer analysis was performed using the Optimas Image Analysis Program (Data Cell, Reading, UK). ${ }^{18}$ Villous height and crypt depth ( $\mu$ meters) were measured. Results were expressed as villous height/mucosal thickness ratios (VH/MT) where mucosal thickness is the sum of villous height and crypt depth. Lymphocyte infiltration of the epithelium was assessed and the results were expressed as intraepithelial lymphocyte counts per 100 enterocytes (IEL); at least 500 enterocytes were counted per specimen. ${ }^{19}$

\section{DEMOGRAPHIC ASSESSMENT}

Patients were questioned as to their country of birth, date of arrival in the UK, and time since last travel to country of birth. Patients were also asked whether they ate meat or were vegetarian.

\section{STATISTICS}

Standard non-parametric statistical tests (Wilcoxon's rank sum test, Mann-Whitney U test, and Spearman's rank correlation test) were used throughout to compare the groups.

\section{ETHICS}

The study was approved by the Ethics Committee of West Birmingham Health Authority.

\section{Results}

SUBJECTS (TABLE I)

Although the controls were younger, the patient groups were of similar mean age. All patient groups showed a female preponderance. 


\section{INTESTINAL PERMEABILITY}

\section{Mannitol excretion}

Median (total range) six hour mannitol excretion was: white controls $15 \cdot 11 \%(8 \cdot 3-19 \cdot 3)$, white patients $13.93 \%(6 \cdot 1-33 \cdot 3)$, Indian patients $12 \cdot 35 \%(4 \cdot 6-28 \cdot 7)$, Afro-Caribbean patients $12 \cdot 73 \%(3 \cdot 5-29 \cdot 6)$, untreated coeliac patients $7 \cdot 23 \%(3 \cdot 8-9 \cdot 7)$. Mannitol excretion was significantly lower in the coeliac patients than in the other groups $(p<0.01$ MannWhitney $U$ test). There were no significant differences between the other groups.

\section{Lactulose excretion}

Median (total range) six hour lactulose excretion was: white controls $0.325 \%(0 \cdot 13-0.59)$, white patients $0.344 \%(0.02-0.82)$, Indian patients $0.380 \%(0.06-1 \cdot 61)$, Afro-Caribbean patients $0.45 \%(0.03-2.08)$, untreated coeliac patients $0.98 \%(0.91-1 \cdot 83)$. The lactulose excretion was significantly higher in the untreated coeliac patients than in any of the other groups $(p<0.01$ Mann-Whitney U test). Among the other groups lactulose excretion was significantly higher in the Afro-Caribbeans compared with the white groups $(p=0.032)$. There were no other significant differences between the groups.

\section{Lactulose:mannitol percentage excretion ratios (LMER)}

Figure 1 shows LMER for the white controls, the three dyspeptic patient groups, and the untreated coeliac patients. Median (total range) LMER in the five groups were: (a) white controls $0.022(0.012-0.037)$; (b) white patients $0.022 \quad(0.009-0.042) ;(c)$ Indian patients $0.031 \quad(0.008-0.125)$; (d) AfroCaribbean patients $0.033(0.008-0 \cdot 18)$; (e) untreated coeliac patients $0.178(0.106-$ 0.257). Median LMER in the untreated coeliac patients was significantly greater than that of any of the other groups $(p<0.001)$. Among the other groups, LMER of the Indians and Afro-Caribbeans was significantly greater

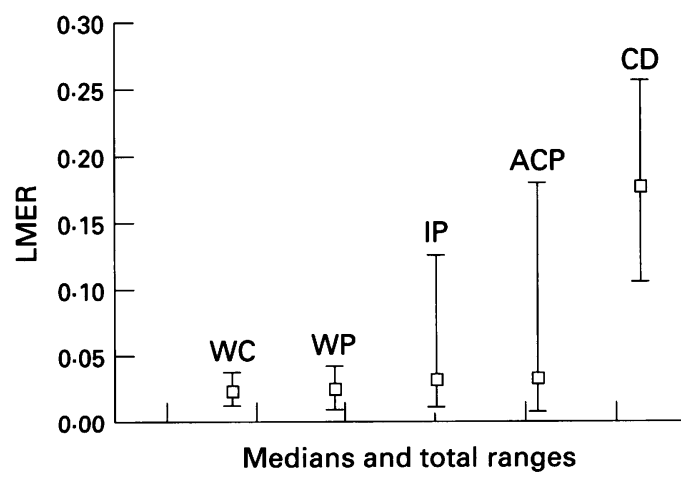

Figure 1: This figure shows lactulose/mannitol excretion ratios (LMER) in white controls (WC), white patients (WP), Indian patients (IP), Afro-Caribbean patients $(A C P)$, and untreated coeliac patients (CP). LMER in the untreated coeliac was greater than that of the other three groups $(p<0.001)$. LMER of the Indians and the Afro-Caribbeans was greater than that of the white groups $(p<0.001)$. There were no differences between the two white groups or between the two immigrant groups.

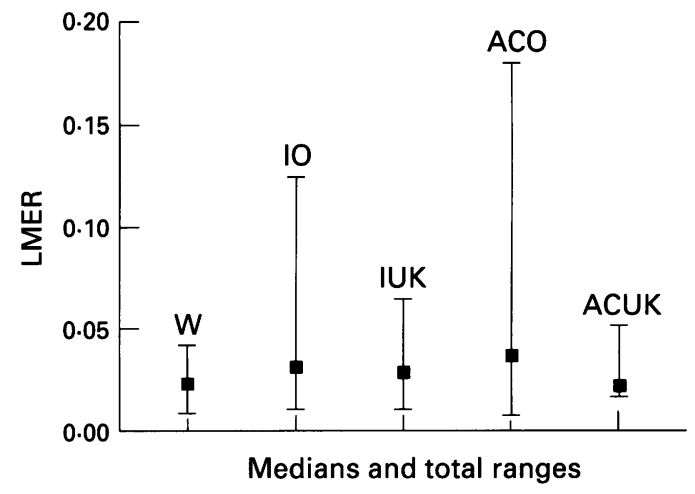

Figure 2: LMER in the white groups (W: controls and patients combined), Indians born overseas (IO), Indians born in the UK (IUK), Afro-Caribbeans born overseas (ACO), and Afro-Caribbeans born in the UK (ACUK). Both groups of immigrants born overseas had LMER greater than that of the white groups $(p<0.001)$. ACUK had LMER no different from that of the white groups. While IUK still had LMER greater than that of the white groups $(p=0.008)$ only $10 \%$ of this group fell outside the normal white range compared with $35 \%$ of the IO group.

than that of the white groups $(p<0.001) ; 33 \%$ Indians and $45 \%$ Afro-Caribbeans had values outside the normal white range. Four otherwise healthy patients (three Afro-Caribbeans and one Indian) fell within the coeliac range. There were no differences between the two white groups or between the two immigrant groups. In the Indian group there were no differences between those of Punjabi or Bengali origin.

Figure 2 shows intestinal permeability in the white groups (controls and patients combined) and in the other patient groups, which were divided with respect to country of birth. Data from the coeliac patients are not shown. Both groups of immigrant origin born abroad had LMER greater than that of the white groups $(p<0.001)$. Of the patients of Indian origin born abroad there was no significant difference in intestinal permeability between those born in Punjab and those born in Bangladesh although both Indian groups had LMER greater than that of the white groups $(p<0.01$ Mann-Whitney U test).

The patients of Afro-Caribbean descent born in the UK had LMER no different from that of the white groups but significantly lower than those of their counterparts born overseas. While the patients of Indian descent born in the UK still had LMERs significantly greater than that of whites $(p=0.008)$, only $10 \%$ of this group fell outside the normal white range compared with $35 \%$ of their counterparts born overseas.

\section{HISTOLOGY (TABLE II)}

No patient had partial or subtotal villous atrophy. Fifty one per cent of biopsy specimens from the white groups, $45 \%$ from Indians, and $57 \%$ from Afro-Caribbeans were deemed satisfactory for computer aided image analysis. VH/MT ratios were significantly lower in the two groups of immigrant descent born abroad compared with white subjects. There was no difference between the two groups of immigrant descent born abroad. The combined 
TABLE II Histological findings

\begin{tabular}{llll}
\hline & Number & VH/MT & Intraepithelial lymphocytes \\
\hline White groups & 15 & $\begin{array}{l}0 \cdot 76 \\
(0 \cdot 73-0 \cdot 83)\end{array}$ & $5(1-17)$ \\
Indians (born overseas) & 34 & $\begin{array}{l}0 \cdot 71^{\star} \\
(0 \cdot 63-0 \cdot 78)\end{array}$ & $9(2-51)$ \\
Afro-Caribbeans & 18 & $\begin{array}{l}0 \cdot 72^{\star} \\
(0 \cdot 66-0 \cdot 78)\end{array}$ & $8(2-11)$ \\
$\quad$ (born overseas) & $0 \cdot 75$ & $7(3-45)$ \\
Indian and Afro-Caribbeans & 20 & $(0 \cdot 64-0 \cdot 83)$ & \\
\hline (UK born) & & &
\end{tabular}

* Significant difference from the white groups and UK born Indians and Afro-Caribbeans $(\mathrm{p}<0.01)$.

The patients of Indian and Afro-Caribbean origin are divided into those born abroad and those of immigrant descent born in the UK combined and taken as a single group. Data shown as medians and total ranges. significance in the Afro-Caribbean group compared with the white groups and occurring as a trend among the Indians. Mannitol permeation showed no significant differences between the ethnic groups. This implies that the differences in small intestinal permeability are largely due to increased 'leakiness' of the bowel rather than reduced absorptive capacity. The coeliac disease 'control' group had significantly lower mannitol and higher lactulose permeation and LMERs than the other groups. However one patient of Indian and three of Afro-Caribbean origin had LMERs within the coeliac range. This degree of abnormality in intestinal permeability was unexplained as the corresponding small bowel biopsy specimens from these patients did not seem any worse than those from other immigrants and none of the patients had symptoms of intestinal disease. Exclusion of these four 'outliers' from the results did not affect the significance of the LMER differences between the patients of immigrant origin and the white groups.

It is recognised that measurable quantities of lactose may be excreted in the urine in subjects with primary lactase deficiency after ingestion of milk. Kynaston et $a l^{20}$ raised questions about separating lactose and lactulose in the urine of children receiving high lactose diets. In view of these concerns and in recognition of the fact that this study involved subjects from ethnic groups having a high prevalence of primary lactase deficiency, ${ }^{21}$ we have always instructed patients undergoing permeability testing to avoid milk and milk products for 24 hours prior to and for the duration of the test. Moreover, we have not had problems separating lactose from lactulose, the former eluting just prior to lactulose.

Previous workers have demonstrated similar differences in small intestinal permeability among asymptomatic residents of the tropics compared with residents of temperate zones. ${ }^{1516}$ These differences have been found to involve increased permeability to disaccharides among subjects resident in various tropical countries ${ }^{15}$ and both increased permeability to lactulose as well as decreased permeation of the polyhydric alcohol mannitol in the case of normal Sudanese adults. ${ }^{16}$ Neither of these studies involved any assessment of small bowel histology.

This study has confirmed previous work from our unit demonstrating minor degrees of villous atrophy among immigrants from the tropics resident in West Birmingham. ${ }^{9} \mathrm{~A}$ correlation has been demonstrated between the observed differences in small intestinal permeability and morphology. This is consistent with previous work demonstrating correlation between intestinal permeability as measured by combined disaccharide/monosaccharide probes and small bowel morphology both in patients with coeliac disease ${ }^{22}$ and in subjects with lesser degrees of villous atrophy. ${ }^{23}$

While the significance of the observed differences in intestinal permeability and morphology is as yet unclear, the fact that they are much less pronounced in those of immigrant descent born in the UK implies that confirmed our previous finding that minor degrees of villous atrophy occur in these people compared with native white subjects. ${ }^{9}$ The observed change in small intestinal permeability is largely due to increased permeation to lactulose; this difference achieving statistical 
environmental rather than genetic factors may be important in their pathogenesis. This is in accord with the results of early studies on fetuses $^{24}$ and animal experiments both with germ free animals and isolated loops of small intestine, ${ }^{25}$ which suggested that environmental factor(s) may be of importance in the pathogenesis of tropical enteropathy. British residents with evidence of tropical enteropathy do not have identifiable haematological or biochemical abnormalities nor is there any evidence that the enteropathy has any relation to height and weight. ${ }^{9}$

The finding of greater abnormalities of intestinal permeability among second generation Indians compared with second generation Afro-Caribbeans is unexplained. It is of interest, however, that patients of Indian descent born in the UK tended to travel to their parent's country of origin much more frequently than the UK born Afro-Caribbeans. Only one of 18 UK born Indians had never travelled to the Indian sub-continent and most had travelled frequently to the tropics. This is in contradistinction to the AfroCaribbeans of whom most (seven of 11) had never travelled to the Caribbean. Although we were unable to show any direct correlation between demographic factors and intestinal permeability one might speculate that a possible explanation for the difference in intestinal permeability between second generation Indians and Afro-Caribbeans may lie in the relative frequency of foreign travel and the comparatively greater LMER among the UK born Indians reflected more frequent exposure of the gut to a tropical environment.

No evidence of intestinal parasitosis was found in any of the patients although rigorous attempts were not made in this to exclude previous intestinal parasitosis. It is possible that the differences in intestinal structure and permeability shown may be a reflection of past or present subclinical parasitic infestation and this deserves further study particularly in view of the presence of higher circulating IgE concentrations among immigrants from the tropic compared with indigenous whites. ${ }^{26}$

While no clear difference in small intestinal permeability or histology was shown between meat eaters and vegetarians in this study, previous work has suggested that ingestion of spices may increase intestinal permeability to various probe markers. ${ }^{27}$ However in that short study no intestinal mucosal damage was seen and it was suggested that the increased intestinal permeation was due to changes in mucosal blood flow or other 'premucosal' factors. In the light of these findings and Lindenbaum's work on the effects of local diet on small intestinal structure and xylose absorption among asymptomatic Americans in Pakistan, ${ }^{5}$ the effects of individual dietary constituents on intestinal permeability deserves further study.

In conclusion we have found significant abnormalities in small intestinal morphology and permeability in otherwise healthy asymptomatic immigrants from the tropics resident in a British inner city compared with native white people; the consequences of these abnormalities remain unknown. Our findings suggest that particular care must be taken in the interpretation of the results of small intestinal investigations in patients born in the tropics.

This study was presented in part at the British Society of Gastroenterology (Gut 1994; 35 (suppl 2): S28) and at Digestive Diseases Week (Gastroenterology 1994; 106: A420).

1 Baker SJ, Ignatius M, Mathan VI, Vaish SK, Chacko CJG. Intestinal biopsy in tropical sprue. In: Wolstenholme $\mathrm{GEW}$, Cameron MP, eds. Intestinal biopsy. London: Churchill, 1982: 84-101.

2 Sprinz H, Sribhibhadh R, Gangarosa EJ, Benyajati C, Kundel D, Halstead S. Biopsy of small bowel in Tha people. Am f Clin Nutr 1962; 38: 43-51.

3 Klipstein FA. Sprue and subclinical malabsorption in the tropics. Lancet 1979; i: 299-305.

4 Sheehy TW, Legters LJ, Wallace DK. Tropical jejunitis in Americans serving in Vietnam. Am $f$ Clin Nutr 1968; 21 : Americans

5 Lindenbaum J, Kent TH, Sprinz H. Malabsorption and jejunitis in American Peace Corps Volunteers in Pakistan. Ann Intern Med 1966; 65: 1201-9.

6 Lindenbaum J, Gerson CD, Kent TH. Recovery of small intestinal structure and function after residence in the tropics. Ann Intern Med 1971; 74: 218-22.

7 Gerson CD, Kent TH, Saha JR, Siddiqi N, Lindenbaum J. Recovery of small intestinal structure and function after residence in the tropics. II. Studies in Indians and Pakistanis living in New York City. Ann Intern Med 1971; 75: 41-8.

8 Klipstein FA, Falaiye JM. Tropical sprue in expatriates from the tropics living in the continental United States. the tropics living in the
Medicine 1969; 48: 475-91.

9 Wood GM, Gearty JC, Cooper BT. Small bowel morphology in British Indian and Afro-Caribbean subjects: evidence of tropical enteropathy. Gut 1991; 32: 256-9.

10 Fourman LPR. The absorption of xylose in steatorrhoea. Clin Sci 1948; 6: 289-94.

11 Baker SJ, Jacob R, Mathan VI. An evaluation of the $5 \mathrm{~g}$ D-xylose absorption test, with fractional urine collections, in subjects living in Southern India. Indian $\mathcal{F}$ Med Res 1971; 59: 1869-77.

12 Csaky TZ, Lassen UV. Active intestinal transport of D-xylose. Biochim Biophys Acta 1964; 82: 215-7.

13 Cooper BT. Tests of small intestinal permeability in clinical practice. F Clin Gastroenterol 1984; 6: 499-500.

14 Cobden I, Dickinson RJ, Rothwell J, Axon ATR. Intestinal permeability assessed by excretion ratios of two molecules: results in coeliac disease. $B M F$ 1978; ii: 1060.

15 Jenkins AP, Menzies IS, Nukajam WS, Grellier L, Mathan VI, Creamer B. Geographic variation in intestinal permeability. Gut 1986; 27: A1509-10.

16 Ukabam SO, Homeida MMA, Cooper BT. Abnormal intestinal permeability in asymptomatic residents of Sudan. Trans Roy Soc Trop Med Hyg 1986; 80: 204-7

17 Fleming SC, Kapembwa MS, Laker MF, Levin GE, Griffin GE. Rapid and simultaneous determination of lactulose and mannitol in urine, by HPLC with pulsed amperometric detection, for use in studies of intestinal permeability. Clin Chem 1990; 36: 797-9.

18 Slavin G, Sowter C, Robertson K, McDermott S, Paton K. Measurement in jejunal biopsies by computer-aided microscopy. f Clin Pathol 1980; 33: 254-61.

19 Ferguson A, Murray D. Quantitation of intraepithelial lymphocytes in human jejunum. Gut 1971; 12: 988-94. 20 Kynaston JA, Fleming SC, Laker MF, Pearson DJ. Simultaneous quantification of mannitol, 3-O-methyl glucose, and lactulose in urine by HPLC with pulsed amperometric detection, for use in studies of intestinal amperometric detection, for use in studies

21 Iqbal TH, Wood GM, Lewis KO, Leek JP, Cooper BT. Prevalence of primary lactase deficiency in adult residents of west Birmingham. BMF 1993; 306: 1303.

22 Ukabam SO, Cooper BT. Small intestinal permeability as an indicator of jejunal mucosal recovery in patients with celiac sprue on a gluten-free diet. $\mathcal{f}$ Clin Gastroenterol 1985; 7: 232-6. 23 Juby LD, Dixon MF, Axon ATR. Abnormal intestinal per-
meability and jejunal morphometry. Clin Pathol 1987; 40: 714-8.

24 Chacko CJG, Paulson KA, Mathan VI, Baker SJ. The villus structure of the small intestine in the Tropics: a necropsy structure of the small intestine in

25 Chacko CJG, Mathan VI, Baker SJ. Changes in the mucosal pattern of isolated loops of jejunal in Albino rats. Br $\mathcal{F}$ Exp
Pathol 1968; 49: 40-3.

26 Benfield GFA, Montgomery RD, Asquith P. Ulcerative colitis in Asian immigrants. Postgrad Med $\mathcal{f}$ 1987; 63: 629-35.

27 Bjarnason I, Levi S, Smethurst P, Menzies IS, Levi AJ. Vindaloo and you. $B M \mathcal{F}$ 1988; 297: 1629-31. 